Environmental Modelling and Software, Volume 111, January 2019, pp. 311-323

DOI: $10.1016 /$ j.envsoft.2018.09.006

\title{
A multiscale statistical method to identify potential areas of hyporheic exchange for river restoration planning
}

\author{
Chiara Magliozzi ${ }^{\mathrm{a}}$, Gianpaolo Coro ${ }^{\mathrm{b}}$, Robert Grabowski ${ }^{\mathrm{a}, *}$, Aaron I. \\ Packman $^{\mathrm{c}}$, Stefan Krause ${ }^{\mathrm{d}}$ \\ ${ }^{a}$ School of Water, Energy and Environment Cranfield University, Cranfield, Bedfordshire \\ $M K 430 A L$ \\ ${ }^{b}$ Istituto di Scienza e Tecnologie dell'Informazione "Alessandro Faedo"- CNR, via \\ Moruzzi 1, 56124 Pisa, Italy \\ ${ }^{c}$ Department of Civil and Environmental Engineering, Northwestern University, \\ Evanston, Illinois, USA \\ ${ }^{d}$ School of Geography, Earth and Environmental Sciences, University of Birmingham, \\ Birmingham, Edgbaston B15 2TT, United Kingdom
}

\begin{abstract}
The hyporheic zone (HZ) is an area of interaction between surface and ground waters present in and around river beds. Bidirectional mixing within the HZ, termed hyporheic exchange flow (HEF), plays significant roles in nutrient transport, organic matter and biogeochemical processing in rivers. The functional importance of the HZ in river ecology and hydrology suggests that river managers should consider the $\mathrm{HZ}$ in their planning to help compromised systems recover. However, current river restoration planning tools do not take into account the HZ. This paper describes a novel multiscale, transferable method that combines existing environmental information at different
\end{abstract}

\footnotetext{
${ }^{*}$ Corresponding author

Email address: r.c.grabowski@cranfield.ac.uk (Robert Grabowski)
} 
spatial scales to identify areas with potentially significant HEF for use in restoration prioritization and planning. It uses a deductive approach that is suited for data-poor case studies, which is common for most rivers, given the very limited data on the spatial occurrence of areas of hyporheic exchange. Results on nine contrasting European rivers, demonstrate its potential to inform river management.

Keywords: hyporheic zone, statistics, hyporheic exchange flow, cluster analysis, catchment management, river basin management

\section{Introduction}

The hyporheic zone (HZ) (Orghidan, 1959) is a region where surface and ground waters mix together within the bed and banks of a river. It is characterized by a diverse fauna and by a bidirectional flow of water known as hyporheic exchange flow (HEF) (Robertson and Wood, 2010). A large body of scientific literature has shown that both the physical and the biological components of the HZ play a major role in river functioning (Findlay, 1995; Brunke and Gonser, 1997; Krause et al., 2011). HEF is important for nutrient transport and cycling (Triska et al., 1993; Battin et al., 2008), stream water temperature variation (Dugdale et al., 2018), contaminant deposition and breakdown (Palumbo-Roe et al., 2017; Fuller and Harvey, 2000), organic matter processing (Sobczak and Findlay, 2002; Zarnetske et al., 2011; Drummond et al., 2014; Danczak et al., 2016) and the distribution and abundance of ecological communities (Dole-Olivier et al., 2014; Boulton, 2007; Battin 
et al., 2016). Perhaps the best-known examples of the importance of HEF on driving ecological processes concern the supply of oxygen into the sediment (Corson-Rikert et al., 2016; Gibbins et al., 2016) and the modulation of biogeochemical transformation (i.e. denitrification and nitrification processes) (Wood and Armitage, 1999; Mendoza-Lera and Datry, 2017; Nogaro et al., 2010; Heppell et al., 2014). As result of the strong and growing scientific evidence that HEF support ecosystem level processes in river systems, restoration practitioners have started to incorporate measures that promote HEF to mitigate water quality impacts, support biodiversity and increase ecological resilience (Hester and Gooseff, 2011; Mendoza-Lera and Datry, 2017).

Restoration measures can induce or enhance HEF through the generation of hydraulic gradients (e.g.large wood, step-pools), creation of geomorphological heterogeneity (i.e. bedforms, sediment sorting, meandering, realignment) and reduction in sediment load (e.g. sediment traps) (Hester and Doyle, 2008; Schirmer et al., 2014; Gordon et al., 2013; Tuttle et al., 2014). However, at present there is little guidance on appropriate siting of restoration measures to locations where HEF has the greatest potential to be enhanced. Furthermore, most of the hyporheic-restoration work has thus far focused on in-channel factors, and has not expressly considered the hierarchy of processes at larger spatial scales that may influence HEF. As HEF is defined by the interaction between surface and groundwater, both surface and subsurface conditions influence the occurrence of HEF at multiple spatial scales 
(Boano et al., 2014). In fact, hyporheic exchange exhibits scale-dependency where HEF at reach and sub-reach scale is influenced significantly by largerscale hydrogeological patterns and processes (Boano et al., 2006; Wörman et al., 2007; Cardenas, 2007, 2008; Stonedahl et al., 2010; Aubeneau et al., 2015). This fractal dimension to HEF (Wörman et al., 2007) means that the occurrence, rates, spatial patterns and temporal variability of HEF are determined by the interaction of physical, chemical and biological processes in the river valley and catchment (Boano et al., 2014; Ward, 2016). There are a large number of factors that influence these processes, which can be divided into five broad and overlapping categories: (1) hydrological, (2) hydrogeological, (3) topographic, (4) anthropogenic and (5) ecological (Table A1 in Supplementary Material, Table 1, Table 2). Currently no framework exists to represent the complexity of multiple inter-related and cross-scale processes affecting the importance of HEF, taking account of typical data availability (Ward, 2016), in river restoration prioritization and planning. Several analytical, probabilistic, and deterministic approaches have been developed to quantify and predict HEF (e.g. stream - tracer injection experiments, one- dimensional advection, dispersion, transient storage models, river network models) (Hester et al., 2017; Cardenas, 2015; Gomez-Velez and Harvey, 2014; Boano et al., 2014; Cardenas, 2008; Cardenas and Wilson, 2007; Cardenas et al., 2004; Kasahara and Wondzell, 2003; Storey et al., 2003; Wroblicky et al., 1998; Wondzell and Swanson, 1996; Harvey and Bencala, 1993). These different modelling approaches have helped to disentangle the 
mechanisms driving hyporheic mixing from a theoretical perspective and to quantify HEF at very fine scales, e.g. sub-reach. Where detailed topographical data are available, approaches based on channel planform and bedforms, like NEXSS, are applicable (Gomez-Velez and Harvey, 2014) However, the bathymetric data needed to accurately map channel bedforms for NEXSS are only available for a limited number of rivers, either large navigable lowland rivers, like the Mississippi (Gomez-Velez and Harvey, 2014), or headwater streams with low turbidity, for which bathymetry data can be measured using bathymetric LiDAR or photogrammetric techniques (for a review, see Grabowski et al. (2014)). Consequently, such approaches are not suitable for initial evaluation of hyporheic exchange for all channels in a river network in most catchments.

Alternatives to these methods are hydrological classifications approaches, which have been identified as both organizing frameworks and scientific tools for river research and management (Olden et al., 2012). Those approaches are common in the literature because they integrate factors and principles controlling hydrological processes and the causes of variations (Olden et al., 2012). They have several advantages: they are geographically independent and use available high-quality hydrological, geological, topographical and ecological datasets that make deductive reasoning a valid approach to define spatial patterns in hydrological characteristics (Olden et al., 2012). The deductive approach requires an accurate choice of environmental factors and the underlying process-interactions in order to ensure that the data are rep- 
resentative of the total existing variation (Kennard et al., 2010).

Restoration measures could be used at different scales to promote HEF, but tools are needed for practitioners that target the HZ to help them prioritize restoration sites, select approaches (i.e. measures) and monitor physical and ecological responses (Palmer et al., 2010; Hester and Gooseff, 2011; Hester et al., 2016; Mendoza-Lera and Datry, 2017). In this paper we propose a novel and transferable method to identify potential areas of HEF in river networks by combining and evaluating environmental data at reach, segment, and catchment scales. The multiscale method merges statistical analyses with a priori knowledge on the processes controlling the HEF and their relationships to provide an assessment of HEF across broad spatial scales and where the availability of measured or modelled hyporheic data is scarce or absent. This deductive approach, using high-quality hydrologically-relevant environmental datasets that relate to the processes that enhance or limit $\mathrm{HEF}$, avoids the reliance on detailed site-specific information of $\mathrm{HEF}$, which is rarely available for most rivers, to inform restoration prioritisation and planning.

\section{Material and Methods}

In this research, we developed and applied a multiscale statistical method to identify potential suitable areas for HEF-focused restoration (Figure 1). The term suitable refers to conditions where factors indicate that HEF has

the potential to exist. The method is used in hierarchy and consists of a 
supervised system that classifies HEF at three spatial scales (catchment, segment and reach). It is based on environmental factors that hydrological theory suggests be related with hyporheic flow (Table 1, 2 and Table A1 in Supplementary Material) but which association to diagnose HEF in river systems has not been studied. The multiscale method represents a deductive approach to HEF classification that is geographically independent and depicted by a mosaic of factors across the catchment. It uses readily available spatially comprehensive datasets rather than extensive hyporheic data as inputs, cause those are often not available at scales of analysis greater than sub-reach and reach scale $(>100 \mathrm{~m})$, and finally expert knowledge. In this paper we present the application of the method to three scales, but the formulae and the rationale explained are applicable to a finer resolution of scales. The multiscale statistical approach involves a series of steps applied sequentially to the harmonized data at catchment, segment and reach scales (Figure 1):

1. Step 1: Variable subsetting- the definition of several subsets of variables from factors that are identified as linked to HEF (Section 2.2). The outcome of Step 1 is a set of testable datasets.

2. Step 2: Variable selection - uses exploratory data mining techniques (PCA and X-Means cluster analysis) to reduce the dimensionality of the input space from Step 1 and to identify factors that are the most related to potential HEF. The outcome of Step 2 is several clusters from each of the tested subsets from Step 1 (Section 2.3). 
3. Step 3: Hyporheic classifier - the semantic characterization of clusters and the assignment of a classifier 1 (i.e., suitable) and 0 (i.e., unsuitable) for every cluster in each tested subsets by an expert (Section 2.4).

4. Step 4: Classifier merger - uses a mathematical combination function to merge the classifier produced for each cluster and each subset by Step 3 (Section 2.5). The output of Step 4 is a single dataset of the merged cluster classifiers across subsets.

5. Step 5: Large scale information merger - the final step involves the application of a mathematical combination function to join the output of Step 4 from one scale with the next larger scale (Section 2.6). The output of Step 5 is a single dataset of the merged cluster classifiers across scales.

The end result of the classification is a binary classification of suitable and unsuitable areas of HEF for clusters of unique variable combinations at each spatial scale (Figure 1). The algorithm was developed using the R scripting language (R Core Team, 2015) and relies on the implementations of X-Means ${ }^{1}$ running on the D4Science ${ }^{2}$ services (Coro et al., 2013, 2015)(Figure 1).

\footnotetext{
${ }^{1}$ https://i-marine.d4science.org/group/biodiversitylab/data-miner? OperatorId=org . gcube . dataanalysis . wps . statisticalmanager . synchserver. mappedclasses.clusterers. XMEANS

${ }^{2}$ https://i-marine.d4science.org/group/biodiversitylab/data-miner
} 


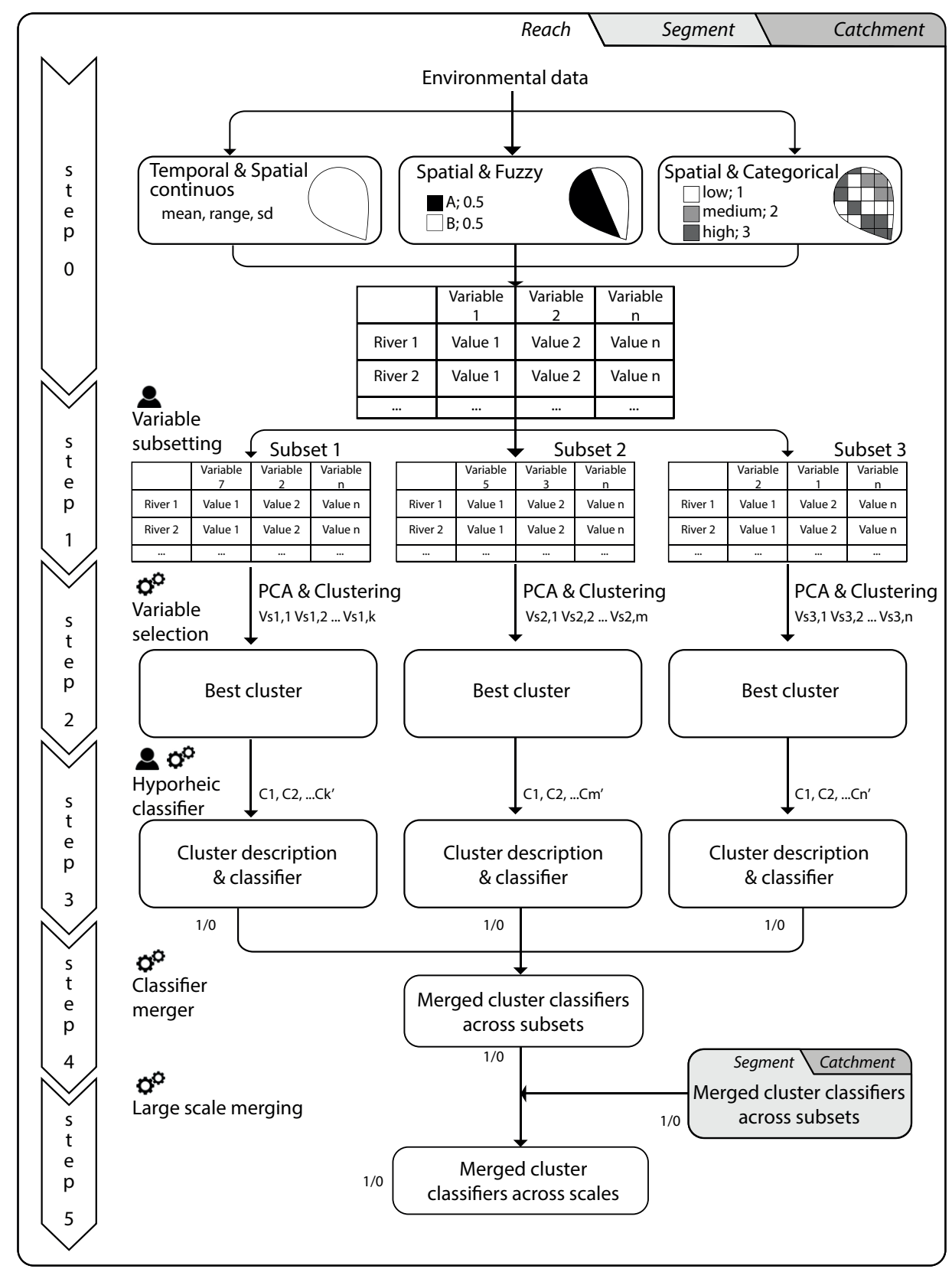

Figure 1: Main steps of the method including Step 1 "Variables subsetting" (Section 2.2), Step 2 "Variables selection"(Section 2.3), Step 3 "Hyporheic classifiers" (Section 2.4), Step 4 "Classifier merger" (Section 2.5), Step 5 "Large scale information merging" (Section 2.6). Cog wheels refer to automatized steps while the person symbol refers to expert supervised steps. 


\subsection{Environmental Data}

\subsubsection{Selection of environmental data}

The environmental data used to develop our method consisted of factors identified in the literature as potential influencing HEF within detailed studies. The association of these factors to diagnose hyporheic conditions in river system has not been studied before. Data were retrieved from remotely sensed and national datasets and consisted of hydrological, hydrogeological, topographic, anthropogenic and ecological factors (Table 1, Table 2). Hydro-

logical factors related to the quantity of water entering and flowing through the catchment, and expression of surface and groundwater flows, includes river and groundwater discharge (Dragoni and Sukhija, 2008; Ward et al., 2012; Voltz et al., 2013). Hydrogeology encompasses factors that affect the distribution of groundwater in aquifers and subsurface flows: geologic properties (porosity, grain size, hydraulic conductivity), heterogeneity of rocks, type of aquifers and soils (Brunke and Gonser, 1997; Kasahara and Wondzell, 2003; Jones et al., 2008; Packman et al., 2006; Bardini et al., 2012; Hartwig and Borchardt, 2015; Kasahara et al., 2013). Topographic factors were included because topography produces discontinuities in the direction of groundwater

flows, thus determining areas of groundwater discharge and recharge, and of stream gradient and channel sinuosity (Anderson et al., 2005; Boano et al., 2006; Wörman et al., 2006, 2007; Caruso et al., 2016). Similar to topography and hydrogeology, anthropogenic factors influence HEF at multiple spatial and temporal scales. For instance, land cover and use (e.g. agricultural 
practices) were included as a factor because directly impacting on evapotranspiration, surface runoff, soil compaction, and erosion at valley scale, all of which significantly impact on river hydrology and might represent a sediment source to reduce HEF (Ryan et al., 2010; Didoné et al., 2014). Finally, ecological factors related to the river-valley lateral and vertical hydrological connectivity include riparian, in-channel vegetation, and in-channel wood. Vegetation dynamics can potentially feedback on the temporal variability of HEF and likely increase the spatial heterogeneity of this ecological- hydrological relationship. 
Table 1: Environmental data for the UK case studies

\begin{tabular}{|c|c|c|c|c|}
\hline Variables & Dataset & Format & Resolution & Source \\
\hline Elevation & $\begin{array}{l}\text { DTM, } \\
\text { LIDAR }\end{array}$ & $\begin{array}{l}\text { ASCII } \\
\text { GRID }\end{array}$ & $\begin{array}{l}5 \mathrm{~m} \\
1 \mathrm{~m}\end{array}$ & Digimap \\
\hline $\begin{array}{l}\text { Bedrock; } \\
\text { Superficial } \\
\text { Geology }\end{array}$ & $\begin{array}{l}\text { Bedrock } \\
\text { Superficial } \\
\text { Geology }\end{array}$ & Shapefile & $\begin{array}{l}1: 50,000 \\
1: 625,000\end{array}$ & $\begin{array}{l}\text { BGS50 } \\
\text { BGS625 }\end{array}$ \\
\hline $\begin{array}{l}\text { Soils; } \\
\text { Aquifers }\end{array}$ & $\begin{array}{l}\text { European } \\
\text { Soil Database; } \\
\text { Groundwater } \\
\text { Resources maps } \\
\text { of Europe }\end{array}$ & Shapefile & $\begin{array}{l}1: 1,000,000 \\
1: 500,000\end{array}$ & $\begin{array}{l}\text { ESDAC } \\
\text { JRC }\end{array}$ \\
\hline Vegetation & $\begin{array}{l}\text { Land Cover } 2007 \\
\text { River Habitat } \\
\text { Survey }\end{array}$ & $\begin{array}{l}\text { GeoTIFF } \\
\text { raw data }\end{array}$ & $25 \mathrm{~m}$ & $\begin{array}{l}\mathrm{CEH} \\
\mathrm{EA}\end{array}$ \\
\hline Precipitation & $\begin{array}{l}\text { Gridded } \\
\text { monthly } \\
1981-2010\end{array}$ & $\begin{array}{l}\text { ASCII } \\
\text { GRID }\end{array}$ & $5 \mathrm{~km}$ & MetOffice \\
\hline Air Temperature & $\begin{array}{l}\text { Gridded } \\
\text { daily } \\
1981-2010\end{array}$ & $\begin{array}{l}\text { ASCII } \\
\text { GRID }\end{array}$ & $5 \mathrm{~km}$ & MetOffice \\
\hline River Flows & Mean daily & Discharge & $\begin{array}{l}\text { Point } \\
\text { data }\end{array}$ & $\begin{array}{l}\text { EA, } \\
\text { CEH }\end{array}$ \\
\hline $\begin{array}{l}\text { Bank; } \\
\text { in-channel } \\
\text { geology }\end{array}$ & $\begin{array}{l}\text { River Habitat } \\
\text { Survey }\end{array}$ & $\begin{array}{l}\text { Raw data, } \\
\text { miscellaneous }\end{array}$ & $\begin{array}{l}\text { SPoint } \\
\text { data }\end{array}$ & EA \\
\hline $\begin{array}{l}\text { Land Cover } \\
\text { and Use }\end{array}$ & $\begin{array}{l}\text { Land Cover } 2007 \\
\text { River Habitat } \\
\text { Survey }\end{array}$ & GeoTIFF & $25 \mathrm{~m}$ & $\begin{array}{l}\text { CEH } \\
\text { EA }\end{array}$ \\
\hline
\end{tabular}


Table 2: Environmental data for the Polish case study

\begin{tabular}{|c|c|c|c|c|}
\hline Variables & Dataset & Format & Resolution & Source \\
\hline Elevation & DTM & ASCII GRID & $\begin{array}{l}25 \mathrm{~m} \\
10 \mathrm{~cm}\end{array}$ & $\begin{array}{l}\text { EEA } \\
\text { BNP }\end{array}$ \\
\hline $\begin{array}{l}\text { Bedrock; } \\
\text { Superficial } \\
\text { Geology }\end{array}$ & $\begin{array}{l}\text { Bedrock \& } \\
\text { Superficial } \\
\text { Geology }\end{array}$ & Shapefile & $1: 250,000$ & $\begin{array}{l}\text { GeoLog } \\
\text { BNP }\end{array}$ \\
\hline $\begin{array}{l}\text { Hydrogeology; } \\
\text { Aquifers }\end{array}$ & $\begin{array}{l}\text { Polish } \\
\text { Geological } \\
\text { Institute; } \\
\text { National } \\
\text { Research } \\
\text { Institute }\end{array}$ & Shapefile & $1: 50,000$ & $\begin{array}{l}\mathrm{PSH} \\
\mathrm{BNP}\end{array}$ \\
\hline Precipitation & $\begin{array}{l}\text { Gridded daily } \\
1951-2013\end{array}$ & GeoTIFF & $5 \mathrm{~km}$ & $\begin{array}{l}\text { BNP } \\
\text { (Berezowski et al., 2016) }\end{array}$ \\
\hline $\begin{array}{l}\text { Air } \\
\text { Temperature }\end{array}$ & $\begin{array}{l}\text { Gridded daily } \\
1951-2013\end{array}$ & GeoTIFF & $5 \mathrm{~km}$ & (Berezowski et al., 2016) \\
\hline River Flows & Discharge & Row data & Point data & (Byczkowski and B., 2004) \\
\hline $\begin{array}{l}\text { Groundwater } \\
\text { flows }\end{array}$ & $\begin{array}{l}\text { Groundwater } \\
\text { levels }\end{array}$ & Row data & Point data & $\mathrm{BNP}$ \\
\hline $\begin{array}{l}\text { Soils; } \\
\text { peat depth }\end{array}$ & $\begin{array}{l}\text { Soil type, } \\
\text { peat depth }\end{array}$ & Shapefile & & $\mathrm{BNP}$ \\
\hline Land Cover & CORINE & GeoTIFF & $25 \mathrm{~m}$ & EEA \\
\hline
\end{tabular}

\subsubsection{Spatial discretization and data transformation}

Data pre-processing included spatial delineation of catchments segments and reaches for our case of study. At first, catchment boundaries were delineated using the Hydrology toolset of the Spatial Analyst Toolbox of ArcGIS 10.2. Secondly, segment units, as sections of river that experience similar valley-scale influences and energy conditions, were delineated based on dis- 
continuities in the gradient along the longitudinal profile of the river network and in sub-catchment areas. The number of segments in a catchment was related to the increase in catchment area due to tributary confluences. The confluence was deemed significant when the sub-catchment area drained by the tributary, was greater than $20 \%$ of the main stem catchment area immediately upstream of the junction (Gurnell et al., 2014). River reaches were delineated based primarily on their channel planform. The river channel was divided into sinuosity units based on changes in the axis of the overall planimetric course. The units that differed in sinuosity by more than $10 \%$ were considered separate reaches.

Continuous temporal and spatial variables (i.e. temperature and elevation) were summarized by summary statistics (mean, standard deviation, minimum and maximum) (Figure 1, Table A2 and Table A3 in the Supplementary Material). For spatial fuzzy variables (i.e. bedrock geology) the relative contribution of each bedrock class (i.e. chalk geology) was expressed as percentage of occupied surface area with respect to the variable overall area and then scale in the range 0 and 1 (Figure 1, Table A2 and Table A3 in the Supplementary Material). Spatial categorical variables as permeability classes, were numerically ranked according to the number of classes (i.e. very high $=4$, high $=3$, low $=2$, very low $=1)($ Figure 1 , Table A2 and Table A3 in the Supplementary Material). 


\subsection{Step 1- Variables subsetting}

The full set of data containing the environmental variables for all case study, is manually subset into groups of variables. This is a necessary preliminary step to statistical discriminant analysis, otherwise not directly applicable given the large set of information reporting dependent variables, noise or missing data. Furthermore, there are usually more variables than rivers that cause difficulties in identify similarity between variables of each group of rivers and minimize the similarity between groups using statistical discriminant analysis. These subsets can contain overlapping variables (e.g. sharing one variable) and can be semantically driven (e.g. subset of aquifer

type or temperature ranges) (Figure 1). The subsets will be analyzed independently. At the end, the independent analysis of multiple variable subsets will provide information about discarded variables that are not correlated to HEF in either Step 2 or Step 4.

\subsection{Step 2- Variables selection}

In Step 2, the variable subsets are analysed independently using principal component analysis (PCA) to explore patterns in data variability among rivers and then complemented by cluster analysis to identify combinations of variables possibly indicating hyporheic responses in a given river area. First, a PCA is performed to reduce the dimensionality of the input space (Jolliffe, 2002). By selecting only the principal components associated with the largest eigenvalues, new vectors are obtained in the transformed-space 
that have smaller dimensions. These vectors are associated to the largest variance directions of the principal components and hence selected for the cluster analysis (variables selection) (Figure 2). Discarded variables can still be included and analysed in other variable subsets or scale, if the presence of those variables is known to be important for HEF. At this stage, the reduced dimensional space is optimized with respect to the information (variance) contained in the data, thus facilitating the application of cluster analysis to the PCA output (Ding and He, 2004). Our method uses the distance- based X-Means algorithm (Pelleg et al., 2000) a variant of the most common KMeans (MacQueen, 1967). The X-Means algorithm was chosen after testing the DBScan density-based clustering algorithm (Ester et al., 1996), which did not produce meaningful grouping of the case studies, i.e. in most of the cases vectors were all classified as outliers. Contrarily to K-Means, XMeans requires indicating a minimum and a maximum number of clusters (Kmin and Kmax). The algorithm applies KMeans to the data for all the possible $\mathrm{K}$ values in the indicated range. KMeans finds the best assignment of the vectors to the $\mathrm{K}$ clusters and produces a score for this assignment, based on the average squared distance of the points to their clusters centroids (distortion measure). XMeans reports the output of the KMeans execution that produced the best score. The associated $\mathrm{K}$ is the best number of clusters. XMeans is also more efficient with respect to KMeans, because it uses kdtrees (Bentley, 1975) and blacklisting as support to the processing. The X-Means algorithm (Pelleg et al., 2000) is applied to the PCA-transformed 
vectors, generating optimal grouping (clusters) of vectors according to their distances. Clustering the dimensionally-reduced, PCA-transformed vectors helps to find the best grouping in this space, since the vectors belonging to the same cluster are close in the PCA-transformed space (Ding and He, 2004). Each cluster produced by XMeans is characterized by a centroid, which is a representative vector of the cluster. In our method, the centroid is interpreted as a summary of the characteristics of the cluster in the PCA-transformed space. Re-projecting the clusters centroids to the original space allows obtaining the coordinates of the centroids expressed in terms of the original variables. Re-projection is mathematically possible although the PCA transformed space has reduced dimensionality with respect to the original space. However, during this step, some information is lost, hence our method analyses the distribution of the variables onto the re-projected centroids. Specifically, we calculate the distances between the variable value and the coordinates of the re-projected centroids for each variable. The number of times a centroid coordinate is closest to a real-data value is also recorded. A tolerance threshold of $25 \%$ is applied, before the final clustering, on the features having the most uniform distributions over the centroids. This step allows the selection of variables that are equally distributed over the centroids, and accounts for the loss of information during the re-projection.

The following example illustrates the criteria used to retain or discard the variables. Suppose 2 data clusters are identified for 8 rivers, defined by vectors of elevation, channel gradient and temperature. If 4 elevation values 
are determined to be closest to cluster $\mathrm{A}$ and the other 4 to cluster $\mathrm{B}$, the elevation variable would be retained, because the $25 \%$ tolerance threshold is exceeded (i.e. $>2$ rivers assigned to a cluster). If 2 channel gradient values were assigned to cluster $\mathrm{A}$ and 6 to cluster $\mathrm{B}$, the channel gradient variable would be discarded because the threshold $(>2)$ is not exceeded. And, if 5 temperature values were assigned to cluster $\mathrm{A}$ and 3 to cluster $\mathrm{B}$, temperature would be retained in the analysis. In conclusion, by construction of the PCA algorithm, if the variables are independent and carry high variance, then the PCA-transformed space would correspond to the original space. Thus, the centroids would take all of the variables into account, resulting in equal distributions of the vectors coordinates on the centroids coordinates (Ding and $\mathrm{He}, 2004)$. A variable that is not assigned to a cluster does not indicate a missing value for that cluster, but it has been discarded during the clustering analysis. 


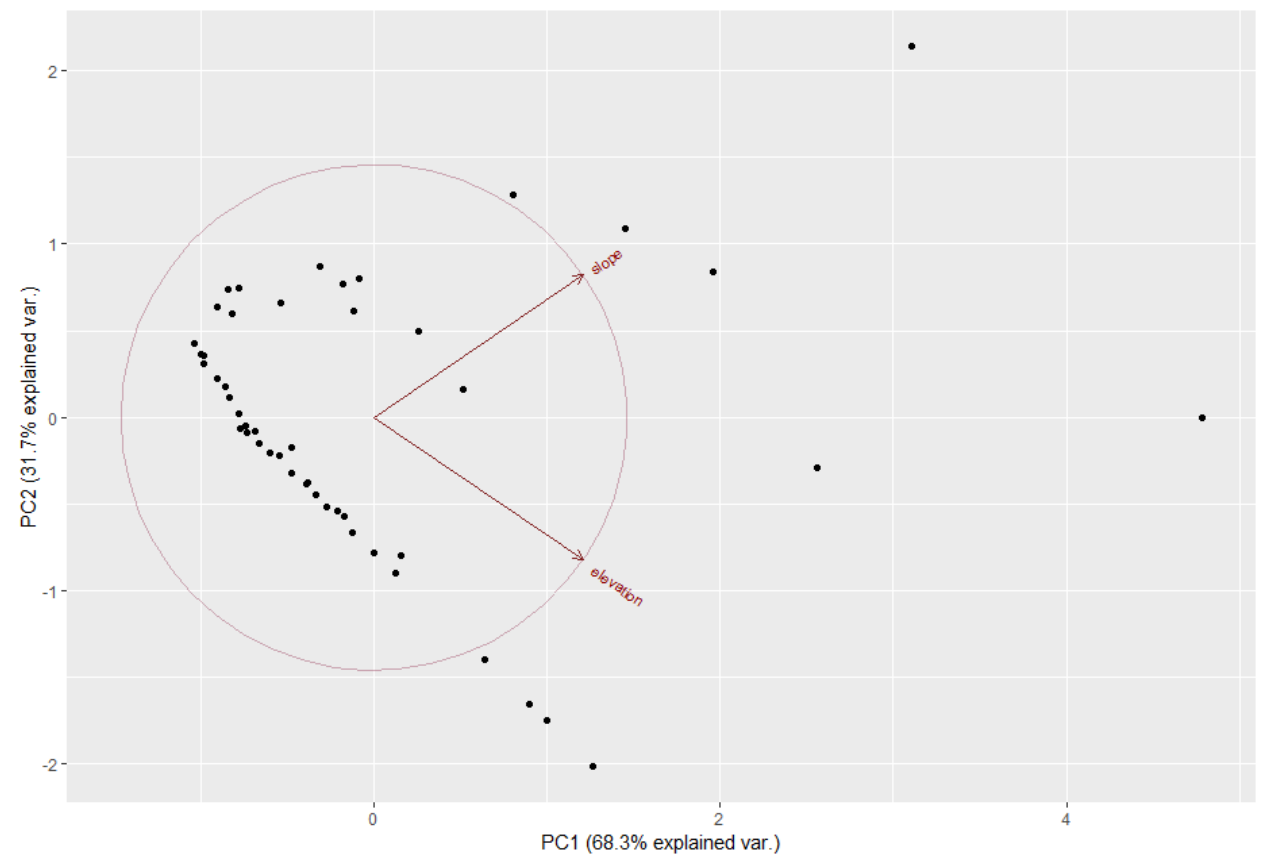

Figure 2: The distribution of the vectors of two variables, average elevation and slope of UK rivers and their related PCAs. The new axes identify the largest variance directions (explained var.); the red circle represents highly correlated points that mostly contribute to the correlation matrix. The values are scaled as requested by the PCA.

\subsection{Step 3-Hyporheic classifiers}

The unique combinations of variables that are generated by the cluster analysis (Step 2), and their centroids are used to assess suitable and unsuitable areas for HEF-restoration for a river area using human expertise. The expert provides a semantic description to each cluster in each subset using the centroid of the cluster and then assigns an hyporheic classifier, 1 (suitable) or 0 (unsuitable), which indicates if the environmental conditions depicted by the clusters lead (i.e. 1) or not (i.e. 0) to HEF. The use of expert knowledge is required because empirical data on HEF is not available for all of 
these unique combinations. The expert bases this assignment on the variable types, the distribution of the variables in each cluster and on the knowledge of the hydrological, hydrogeologic, topographic, anthropogenic and ecological factors that yield HEF following the relationships summarized in Table A1 in the Supplementary Material. At the end of the Step 3, the initial set of variables has been factored into clusters, semantically described and labelled (examples Tables A6, A7, A8 in the Supplementary Material). The next section explains how these clusters are combined, which corrects errors in the cluster label assignment and cluster analysis.

\subsection{Step 4-Classifier merger}

Classifiers for each cluster and subset are merged together using a mathematical combination function. The criterion used for the mathematical combination function is to indicate that areas of $\mathrm{HEF}$ are suitable only if over half of the hyporheic classifiers indicate that it is suitable. The mathematical combination function allows us to account for errors in the hyporheic classifiers due to mis-labelling of the clusters. The combination function is the normalized sum of all the sub-classification for each case study:

$$
\begin{gathered}
C s(r)=\frac{\sum_{i=1}^{N} C_{s_{i}}(r)}{N} \\
C(r)= \begin{cases}1, & C s(r)>50 \% \\
0, & \text { otherwise }\end{cases}
\end{gathered}
$$

where $r$ is the complete set of variables associated to a river area; $s_{i}$ is 
the $i$-th (of $N$ ) variable subset; $C_{s_{i}}(r)$ is the $i$-th binary hyporheic classification over the $s_{i}$ variable subset; $C s(r)$ is the normalised sum of all the sub-classifications for the river area $r$ and $C(r)$ is the final classification function. If $C s(r)$ is higher than $50 \%$, the river area $r$ is classified as suitable, otherwise the classifier assesses unsuitable. This threshold was set after heuristic evaluation of a small (20\%) subset of our data.

\subsection{Step 5- Large scale merging}

To increase the accuracy of predictions as the spatial scale becomes finer, the last step of the method is to combine the binary classifiers from different scales using a downscaling approach. The rationale behind the combination function is the following: if the system predicts that HEF areas are suitable in a river at a large spatial scale, then it is more likely to present suitable areas at smaller spatial scales nestled within the larger area. For example, a positive (binary 1) classification at catchment scale suggests that suitable environmental conditions exist for HEF in the catchment area. At this scale of analysis, the accuracy of the classification is generally higher because it is not required to precisely identify the specific location of hyporheic exchange. Hence, a smaller-scale classifier can use the information from a larger-scale classifier because it represents the presence of factors that drive HEF. Our method embeds this approach using a bonus function (20\% weighting in the equation) that combines the output of a classifier with the output of the next-largest-scale classifier. The classification is recalculated for finer scales 
as follows:

$$
\begin{gathered}
\text { Clarge }(r)=C s(r)+20 \% \text { Clargescale }(r) \\
C(r)=\left\{\begin{array}{lc}
1, & \text { Clarge }(r)>50 \% \\
0, & \text { otherwise }
\end{array}\right.
\end{gathered}
$$

Where $C s(r)$ is the normalized sum of all the sub-classifications for river area $r$, and Clargescale $(r)$ is the dichotomic score of the first larger scale. Also in this case, the threshold (50\%) has been set after heuristic analysis on a small $(20 \%)$ subset of our data.

\section{Results}

This section reports the results of the application of the multiscale statistical method to the nine test catchments. The cluster results were compared to expert opinion (Section 3.1) and discussed at each spatial scale (Section $3.2)$. 


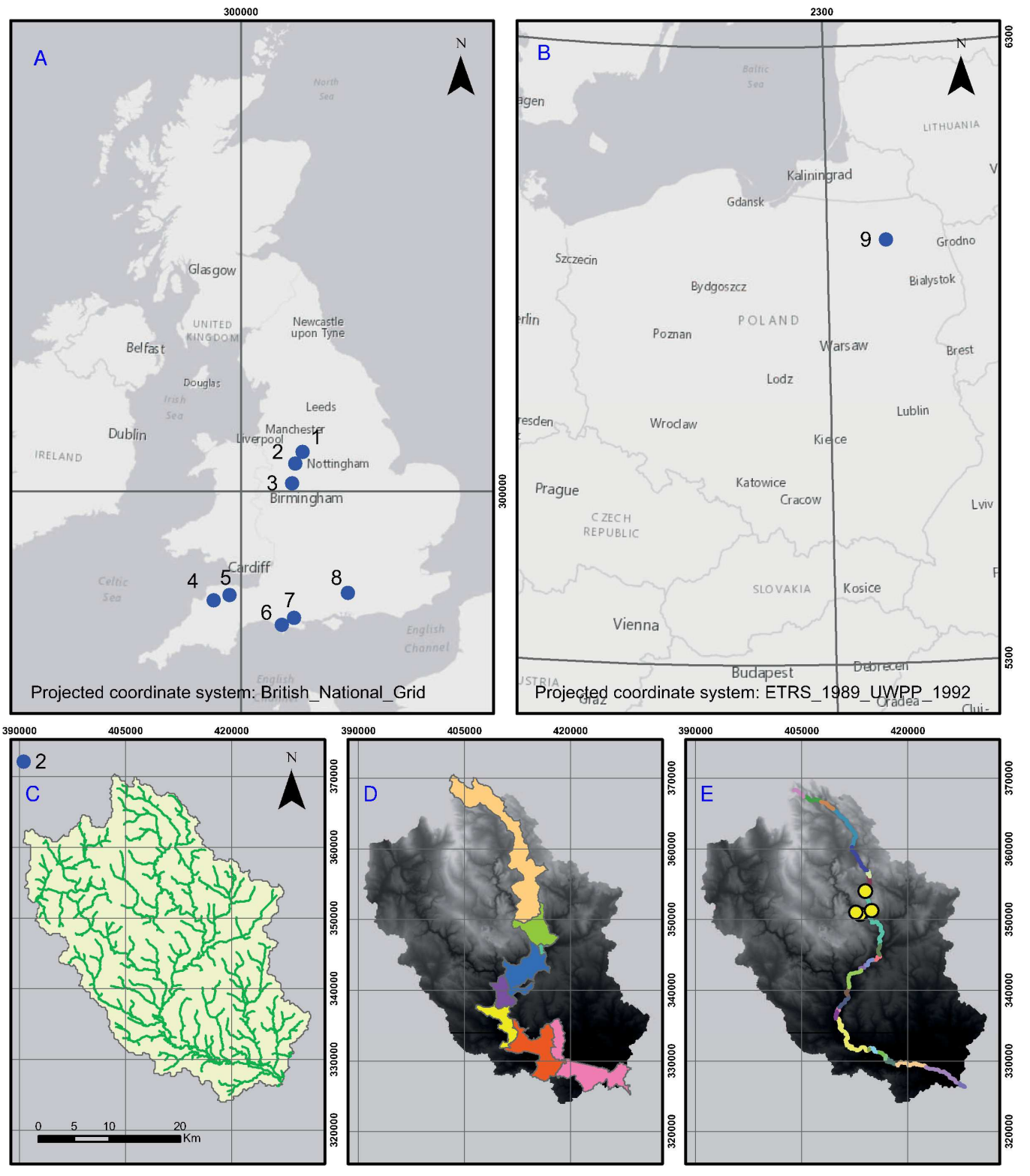

Figure 3: Panels A and B represent the locations of the two cases of study UK (A) and Poland (B). Panels C,D,E represent the River Dove in UK and the examined spatial scales: catchment (C), segments (D), reaches (E). In panel A the numbers refer to: (1) the River Wye,(2) the River Dove, (3) the River Tern, (4) the River Exe, (5) the River Tone, (6) the River Frome, (7) the River Piddle, (8) the River Rother, (9) the River Biebrza. The yellow points in panel $\mathrm{E}$ refer to literature studies carried out on that particular reach of the catchment by Dunscombe (2011). 
Table 3: Selected Rivers in Europe. Coordinates (WGS84) refer to the downstream-most point in the case studied rivers, which was used for catchment delineation

\begin{tabular}{|c|c|c|c|}
\hline $\begin{array}{l}\text { River } \\
\text { catchment }\end{array}$ & $\begin{array}{l}\text { Latitude } \\
\text { Longitude }\end{array}$ & $\begin{array}{l}\text { Catchment Area } \\
\left(\mathrm{km}^{2}\right)\end{array}$ & $\begin{array}{l}\text { Bedrock } \\
\text { Geology }\end{array}$ \\
\hline Dove & $\begin{array}{l}53.207 \\
-1.928\end{array}$ & 212.154 & $\begin{array}{l}\text { Carboniferous } \\
\text { Limestone }\end{array}$ \\
\hline Wye & $\begin{array}{l}53.327 \\
-1.851\end{array}$ & 270.776 & $\begin{array}{l}\text { Carboniferous } \\
\text { Limestone }\end{array}$ \\
\hline Exe & $\begin{array}{l}51.160 \\
-3.830\end{array}$ & 103.162 & $\begin{array}{l}\text { Permo-Triassic } \\
\text { Sandstone }\end{array}$ \\
\hline Tone & $\begin{array}{l}51.088 \\
-3.380\end{array}$ & 461.857 & $\begin{array}{l}\text { Permo-Triassic } \\
\text { Sandstone }\end{array}$ \\
\hline Frome & $\begin{array}{l}50.835 \\
-2.652\end{array}$ & 467.610 & $\begin{array}{l}\text { Cretaceous } \\
\text { Chalk }\end{array}$ \\
\hline Piddle & $\begin{array}{l}50.835 \\
-2.431\end{array}$ & 202.471 & $\begin{array}{l}\text { Cretaceous } \\
\text { Chalk }\end{array}$ \\
\hline Tern & $\begin{array}{l}52.945 \\
-2.336\end{array}$ & 852 & $\begin{array}{l}\text { Permo-Triassic } \\
\text { Sandstone }\end{array}$ \\
\hline Rother & $\begin{array}{l}51.087 \\
-0.926\end{array}$ & 379.795 & $\begin{array}{l}\text { Greensand } \\
\text { Sandstone }\end{array}$ \\
\hline Biebrza & $\begin{array}{l}54.188 \\
22.625\end{array}$ & 7062.618 & $\begin{array}{l}\text { Marl } \\
\text { Sands }\end{array}$ \\
\hline
\end{tabular}

\subsection{Validation and reliability of the classification results}

The X-Means algorithm identified three optimal clusters in all the three spatial scales considered in the study. To evaluate whether the developed multiscale statistical approach could identify suitable and unsuitable areas for hyporheic exchange to occur, the reliability of the identified clusters was 
evaluated by examining the representativeness of the variables among the clusters against human expertise by the authors. In the assessment, the lead author manually assigned one of the interpretations of the XMeans clusters (i.e. 1 or 0 ) to each river catchment (i.e. 8 catchments and 118 variables for the UK case of study; 86 variables for the Polish case study), segment (51 segments and 48 variables for the UK case of study; 10 segments and 35 variables for the Polish case study) and reach (135 reaches and 59 variables for the UK case of study; 11 reaches and 74 variables for the Polish case study). At this stage, the expert evaluation differs from the expert information within the model (Step 4) because it is performed on the original environmental data (Section 2.1) and not on the clusters. A confusion matrix was used to assess the agreement between the expert assignment (binary 1 and 0 ) and X-means clusters as the percentage of matching assignments (absolute percentage of agreement). Furthermore, the Cohen's Kappa (Cohen, 1960) was calculated to estimate the agreement between the expert and the model compared to purely random assignments. The X-Means results agreed generally with expert opinion indicating reliable semantic interpretations of the categories identified in the clusters variations. At catchment scale the absolute percentage of agreement is $88 \%$ and $75 \%$, at segment $75 \%$ and $78 \%$ and at reach $74 \%$ and $82 \%$ for the UK and Polish case studies respectively (Table 4, Table 5). 
Table 4: UK case study: confusion matrix for classification at the catchment, segment and reach scale

\begin{tabular}{|c|c|c|c|}
\hline \multicolumn{4}{|c|}{ Clustering Catchment scale } \\
\hline Expert & Classifier 1 & Classifier 0 & Total \\
\hline Classifier 1 & 4 & 1 & 5 \\
\hline Classifier 0 & 0 & 3 & 3 \\
\hline Total & 4 & 4 & 8 \\
\hline Agreement & 4 & 3 & 7 \\
\hline \multirow[t]{2}{*}{ By Chance } & 2.51 & 1.50 & 4.01 \\
\hline & & Fleiss & Landis-Koch \\
\hline Kappa & 0.75 & Good & Substantial \\
\hline Absolute $\%$ of agreement & $88 \%$ & & \\
\hline \multicolumn{4}{|c|}{ Clustering Segment Scale } \\
\hline Expert & Classifier 1 & Classifiers 0 & Total \\
\hline Classifier 1 & 16 & 7 & 23 \\
\hline Classifiers 0 & 6 & 22 & 28 \\
\hline Total & 22 & 29 & 51 \\
\hline Agreement & 16 & 22 & 38 \\
\hline \multirow[t]{2}{*}{ By Chance } & 9.92 & 15.92 & 25.84 \\
\hline & & Fleiss & Landis-Koch \\
\hline Kappa & 0.48 & Good & Moderate \\
\hline Absolute $\%$ of agreement & $75 \%$ & & \\
\hline \multicolumn{4}{|l|}{ Clustering Reach scale } \\
\hline Expert & Classifier 1 & Classifier 0 & Total \\
\hline Classifier 1 & 25 & 7 & 32 \\
\hline Classifier 0 & 27 & 70 & 97 \\
\hline Total & 52 & 77 & 129 \\
\hline Agreement & 25 & 70 & 95 \\
\hline \multirow[t]{2}{*}{ By Chance } & 12.90 & 57.90 & 70.80 \\
\hline & & Fleiss & Landis-Koch \\
\hline Kappa & 0.42 & Good & Moderate \\
\hline Absolute $\%$ of agreement & $74 \%$ & & \\
\hline
\end{tabular}


Table 5: Polish case study: confusion matrix for classification at the catchment, segment and reach scale

\begin{tabular}{|c|c|c|c|}
\hline \multicolumn{4}{|c|}{ Clustering Catchment scale } \\
\hline Expert & Classifier 1 & Classifier 0 & Total \\
\hline Classifier 1 & 1 & 1 & 2 \\
\hline Classifier 0 & 0 & 2 & 2 \\
\hline Total & 1 & 3 & 4 \\
\hline Agreement & 1 & 2 & 3 \\
\hline \multirow[t]{2}{*}{ By Chance } & 0.52 & 1.53 & 2.31 \\
\hline & & Fleiss & Landis-Koch \\
\hline Kappa & 0.5 & Good & Moderate \\
\hline Absolute $\%$ of agreement & $75 \%$ & & \\
\hline \multicolumn{4}{|c|}{ Clustering Segment scale } \\
\hline Expert & Classifier 1 & Classifiers 0 & Total \\
\hline Classifier 1 & 24 & 9 & 33 \\
\hline Classifiers 0 & 7 & 7 & 7 \\
\hline Total & 24 & 16 & 40 \\
\hline Agreement & 24 & 7 & 31 \\
\hline \multirow[t]{2}{*}{ By Chance } & 19.81 & 2.82 & 22.61 \\
\hline & & Fleiss & Landis-Koch \\
\hline Kappa & 0.48 & Good & Moderate \\
\hline Absolute $\%$ of agreement & $78 \%$ & & \\
\hline \multicolumn{4}{|l|}{ Clustering Reach scale } \\
\hline Expert & Classifier 1 & Classifier 0 & Total \\
\hline Classifier 1 & 3 & 0 & 3 \\
\hline Classifier 0 & 2 & 6 & 8 \\
\hline Total & 5 & 6 & 11 \\
\hline Agreement & 3 & 6 & 9 \\
\hline \multirow[t]{2}{*}{ By Chance } & 1.36 & 4.36 & 5.72 \\
\hline & & Fleiss & Landis-Koch \\
\hline Kappa & 0.62 & Good & Substantial \\
\hline Absolute $\%$ of agreement & $82 \%$ & & \\
\hline
\end{tabular}


As the binary classifiers for each scale in Step 5 take account of the information from the next-largest scale (i.e. catchment classifiers influencing segment classifiers) to represent the scale dependence in HEF, the model performance is expected to increase within decreasing scale. In the UK case of study, the catchment scale effectively added information to the segment scale (Step 5) because the agreement increases of 1 percentage point (Table 6). However, in the Biebrza application, no performance increase was detected (Table A4 in Supplementary Material).

Table 6: UK case study Step 5: confusion matrix segment agreement with enrichment of the $20 \%$ using the information of the catchment

\begin{tabular}{llll}
\hline Clustering Segment-Catchment & \multicolumn{3}{l}{} \\
\hline Expert & Classifier 1 & Classifier 0 & Total \\
Classifier 1 & 22 & 1 & 23 \\
Classifier 0 & 11 & 17 & 28 \\
Total & 33 & 18 & 51 \\
Agreement & 22 & 17 & 39 \\
By Chance & 14.88 & 9.88 & 24.76 \\
\hline & & Fleiss & Landis-Koch \\
Kappa & 0.54 & Good & Moderate \\
Absolute \% of agreement & $\mathbf{7 6 \%}$ & & \\
\hline
\end{tabular}

\subsection{Prediction of HEF at different spatial scales}

HEF suitable and unsuitable areas were predicted at all three spatial scales for the examined rivers (Figure 3, Table 3). At catchment scale, un- 
suitable conditions for HEF are predicted for the Rivers Dove, Exe, Tone and Wye (Figure 4). These rivers are predominantly characterized by confined or semiconfined aquifers, poorly sorted superficial deposits, from coarse sand to silt and clay ( $>50 \%$ cover over the catchment). In contrast, for the Rivers Frome, Piddle, Tern and Rother, the semi-automatic classification method predicts suitable areas for HEF to occur. The clusters for these rivers depict predominantly complex aquifers with flows though fractures and discontinuities, terrigenous deposits with sorted sand and gravel (30 to 45\%), silt and clay deposits less than $20 \%$ of cover on the catchment.

At segment scale, HEF is found to be characterized by suitable areas for all the identified segments in the Rivers Piddle, Tern, Wye and the Biebrza River (Figure 4, Table 3). Conversely, HEF is predicted to be low for all the segments in the Rivers Dove, Rother and Tone. The Rivers Exe and Frome are predicted to have a mixture of suitable and unsuitable HEF areas in different segments. Where suitable HEF condition is predicted, the clusters are mainly characterized by sandstone geology, a low fraction fine sediments (between 10 and $30 \%$ cover over the segments), large fraction of sorted gravel and sand deposits (between 20 and 50\% cover over the segments), channel sinuosity of $\geq 1.2$ and low channel gradient (0.002). In segments with unsuitable conditions for HEF, the clusters describe mudstone and sandstone geology, low channel gradients, high percentage of clay and fines $(>55 \%$ cover $)$ and high percentage of arable and grassland ( $>70 \%$ cover) within $150 \mathrm{~m}$ of the river channel. For the Biebrza River, the segments which are predicted to 
have suitable $\mathrm{HEF}$ conditions are characterized by sinuosity $\geq 1.3$, high percentage of gravel and sand deposits ( $>40 \%$ ), high percentage of productive aquifer, and low percentage of pasture lands $(<10 \%)$ within $150 \mathrm{~m}$ of the main river channel.

Table 7: Frequency of the categories, suitable 1, unsuitable 0 HEF in the catchments, segments, reaches.

\begin{tabular}{ll|l|l|l|l|l}
\hline & \multicolumn{2}{c}{ Catchment } & \multicolumn{3}{|c}{ Segment } & \multicolumn{2}{c}{ Reach } \\
& 1 & 0 & 1 & 0 & 1 & 0 \\
\hline Biver & 1 & - & 10 & - & 5 & 6 \\
Dove & - & 1 & - & 8 & - & 19 \\
Exe & - & 1 & 3 & 4 & - & 16 \\
Frome & 1 & - & 5 & 1 & 37 & 1 \\
Piddle & 1 & - & 4 & - & 15 & 6 \\
Rother & 1 & - & - & 10 & - & 11 \\
Tern & 1 & - & 4 & 0 & - & 9 \\
Tone & - & 1 & - & 6 & - & 10 \\
Wye & - & 1 & 6 & - & - & 11 \\
\hline
\end{tabular}

Finally, at reach scale, the multiscale statistical method predicted suitable HEF areas for 3 rivers of the 9 evaluated: the Frome, Piddle and Biebrza (Figure 4, Table 3). Generally, the clusters indicating suitable conditions for HEF exhibit a low percentage of in-channel vegetation (2-10\% of the reach), gravel substrates $(>10 \%)$, very low percentage of silt and clay deposits $(<1 \%)$, presence of pools and riffles $(5-10 \%)$, and a low percentage of poached 
or overgrazed river banks $(<5 \%)$. Cluster indicating unsuitable HEF areas are mainly described by poached river banks, presence of in-channel emergent vegetation and reeds, low percentage of gravel substrates, low number of pools and riffles, and low mean flow velocity. In the Biebrza River, clusters indicating suitability relate to superficial geology dominated by peat $(80 \%$ cover on the entire reach) and mud (10\%), while those indicating unsuitability are dominated by mud $(60 \%)$ and peat $(<10 \%)$ deposits, low percentage of sand and gravels, and high percentage of unsorted till deposit (>50\%) and pasture lands. 


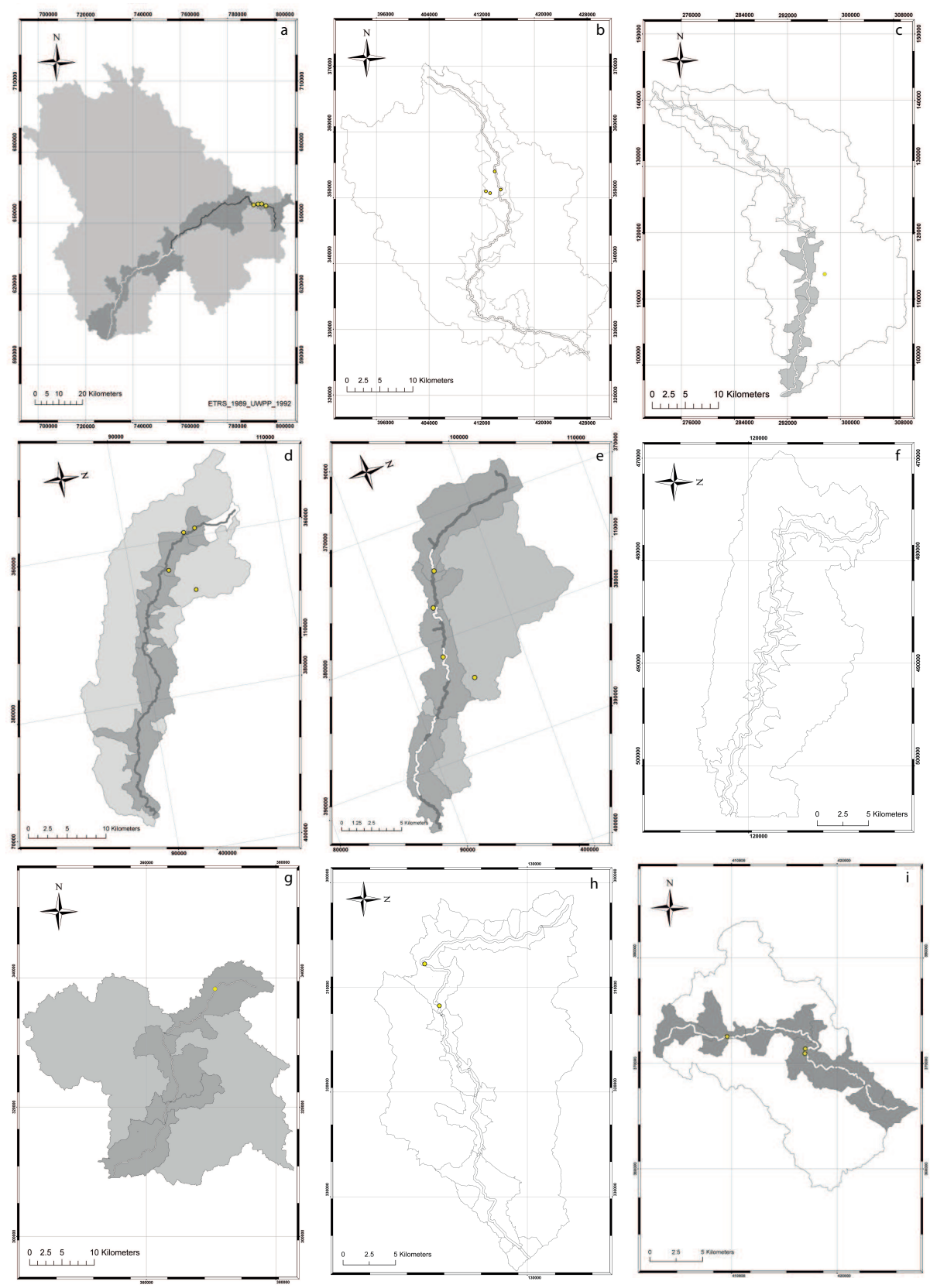

Figure 4: Grey-scale coded maps of the case study rivers based on suitable "1" (grey scale) and unsuitable "0" (white) areas of HEF. a) the Biebrza River, b) the Dove River, c) the Exe River, d) the Frome river, e) the Piddle River, f) the Rother River, g) the Tern River, h) the Tone River, i) the Wye River. Yellow points refer to field data of HEF from Dunscombe (2011); Anibas et al. (2012); Krause et al. (2011). 


\section{Discussion and Conclusion}

The multiscale statistical method was developed and applied to nine rivers across Europe to identify suitable and unsuitable reaches, segments and catchments for HEF-focused restoration. The results of the classification showed good to moderate agreement (Cohen's Kappa) with expert opinion, indicating reliable categories and semantic interpretations of the clusters. Reasonable agreement is also observed with in-situ empirical data from previous studies, given the unavoidable differences in scale between these detailed local research studies $(1 \mathrm{~m}-1 \mathrm{~km})$ and our broad scale approach. In this section we discuss the results of the classification against field observations of actual HEF, the major predictors of suitable and unsuitable areas (Section 4.1) and finally the domain of application of the method (Section 4.2).

\subsection{Linking processes to factors}

At each spatial scale (catchment, segment and reach), cluster results show groups of predictors that influence the determination of suitable and unsuitable areas for HEF-restoration. Hydrological factors (i.e. groundwater level, discharge) influence HEF by changing surface water flow regimes and distributions of hydraulic head (Table A1 Supplementary Material). Hydrogeological factors affect water flowing through the river bed by sediment grain size, sediment heterogeneity, and depth, therefore promoting spatially diverse

hyporheic exchange (Packman and Salehin, 2003), Table A1 Supplementary Material). Topographic factors, such as catchment gradient, individual bed- 
forms and bedforms sequences, valley confinement, author hydrodynamic and hydrostatic forces that affect the variability of HEF from $\mathrm{cm}$ to $\mathrm{km}$ scale (Table A1 Supplementary Material). Anthropogenic factors such as in-channel structures (i.e. weirs, dams), land management and land use, impact HEF by modifying river stage fluctuations, changing sediment delivery and channel complexity, and by altering vertical hydraulic gradients (Table A1 Supplementary Material). Also vegetation has long been known to exert a strong control on land surface hydrology by moderating streamflow and groundwater recharge (Table A1 Supplementary Material). As an ecological factor, vegetation feedbacks on the temporal variability of HEF and likely increase the spatial heterogeneity of this ecological hydrological relationship. This section presents the different factors affecting suitable and unsuitable HEFrestoration areas and compares the HEF predictions at reach scale to in-situ empirical data from previous studies.

High percentages of poached banks, emergent in-channel vegetation, improved grassland, and low geomorphological complexity, and low number of pool-and-riffle sequences, were associated with unsuitable reaches in the Frome (1 reach) and in the Piddle catchments (15 reaches). Dunscombe (2011) observed weak vertical hydraulic gradients (VHGs) at the head and tail of riffles in both the Rivers Frome and Piddle, indicating little to no HEF at this scale. This is a finer scale than the prediction of our model which overall classifies that reach as unsuitable (Figure 4e). These neighboring catchments are found in the south of England and are underlain by chalk 
bedrock. Chalk has a high secondary porosity, and groundwater flows easily through fractures and fissures in the bedrock to these gravel-bed rivers (Waters and Banks, 1997). The combination of a permeable chalk geology and coarse sediment would be expected to strongly support HEF (Morrice et al., 1997; Hiscock, 2007). However, there are several reasons for unsuitable conditions in these rivers: (i) the pronounced groundwater flows create strongly gaining and losing conditions in reaches, which drive contraction (gaining) or expansion (losing) of HZ and shortening of HEF paths (Wondzell and Gooseff, 2013; Fox et al., 2014; Malzone et al., 2015, 2016); ii) the rivers have few instream geomorphic features that would generate advective pore water flow into, through and out of the river bed (Elliott and Brooks, 1997; Tonina and Buffington, 2009); and iii) high fine sediment loads have led to clogging of the coarse gravel bed (Boulton and Hancock, 2006; Pretty et al., 2006). Several studies have shown that chalk rivers in England have elevated fine sediment loads, derived principally from cultivated agricultural land (Walling and Amos, 1999; Collins and Walling, 2007; Grabowski and Gurnell, 2016) and grazing pressure (Trimble and Mendel, 1995; Bilotta and Brazier, 2008; Bilotta et al., 2010). Also, in-channel vegetation appears be an important factor at this scale of analysis. While vegetation patches have been shown to narrow the active channel, increasing water velocities and mobilizing the gravel bed Cotton et al. (2006), the localised reduced velocities within vegetation patches promote deposition of sediment and organic matter, decreasing bed permeability and reducing or eliminating HEF (Salehin et al., 2004; En- 
sign and Doyle, 2005; Corenblit et al., 2007). For the Wye River, the results of the statistical method agreed with Dunscombe (2011) observations (weak VHGs), while for the Rivers Tone, Dove, the predictions did not align with field data. Our method predicts unsuitable areas for HEF at the reach scale along the Tone and the Dove, while Dunscombe (2011) observed strong patterns of up- and downwelling flows at the head and tail of riffles on both rivers. For the River Tern, all reaches were identified as unsuitable areas by our method, however empirical HEF data at a pool-riffle-pool sequence showed temporal flow patterns occurring around this geomorphic feature at the sub-reach scale (Krause et al., 2011; Hannah et al., 2009).

Suitable areas for HEF were predicted consistently across all spatial scales for the Rivers Dove and the Tone, but not for the Tern, Wye, Rother, Piddle, Frome, Exe and Biebrza. At catchment scale, the clusters for the Dove and Tone are characterized by well distributed variables: sandstone is mixed with mudstone and siltstone bedrock geology and clay and silt superficial deposits represent more than the $50 \%$ of the catchment. Similarly, the hydrogeology is dominated by unconfined but low-producing aquifers. While the sandstone bedrock would normally support surface-subsurface exchange (Hiscock, 2007), the low-conductivity superficial deposits characterizing the clusters (more than $50 \%$ of the catchment area) would likely limit or restrict vertical hyporheic flow. Indeed, the role of local sediment deposits in preventing or limiting groundwater-surface water interactions has been recognised for unconfined alluvial channels (Gurnell et al., 2014). At segment scale, 
clusters characterized by low slopes, high percentage of in-channel fine sediments, and extensive arable lands around the river channel are depicted in the clusters, possibly suggesting an impact of sediment delivery from the surrounding lands and simplification of landscape complexity (Gooseff et al., 2007; Boano et al., 2014).

At reach scale, suitable conditions for HEF were predicted in some reaches of the Biebrza, Frome and Piddle (Figure 4). For the Biebrza River, the reaches identified as suitable (Figure 4a) in our classification corresponded in spatial extent to one reach of our analysis, which were previously observed to have upwelling and sections of recharge (Anibas et al., 2012). These reaches were characterized mainly by a geology of peat and peat mixed with mud. Our clusters identified peat as an important variable controlling HEF at the reach scale. This reflects the underlying process controls, as the physical structure and stratigraphy of peat has pronounced influence on the dynamics of water retention, storage and solute transport (Rezanezhad et al., 2016). Anibas et al. (2012)described two main types of peat soils that showed different behaviors in driving HEF flows at the sediment-water interface; soil I has a loose structure, covered in reed vegetation and characterized by high flow fluxes, while soil II is more compact and has lower flow fluxes. In our data for the Biebrza, peat characteristics are heterogeneous across reaches, varying from loose, similar to soil type I, to more compact and mud-dominated, similar to soil type II. Therefore, the overall assessment and spatial distribution of $\mathrm{HEF}$ predictions at reach scale in the Biebrza catchment are supported by 
the findings of Anibas et al. (2012).

A possible reason of the difference in outputs between the predicted HEF conditions by the multiscale approach and in-situ observations is the different spatial and temporal resolutions. In-situ measurements commonly focuses on an individual bedform or feature or sequences of them (i.e. meter to 10s meter scale) are influenced by temporal variations that are not considered in the proposed approach. Moreover, the resolution of geomorphological data used in these case studies is coarser than the detailed, sub-reach-scale observations of HEF. River Habitat Survey (RHS) data was used as point estimates of in-channel conditions. While RHS data is ideal for this type of analyses in many ways (e.g. UK-wide coverage, reach survey scale), it is a visual appraisal of river habitats and geomorphic features, and does not involve topographical or hydrogeological measurements (Raven et al., 1996). RHS assesses river habitat within a $500 \mathrm{~m}$ long reach using 10 "spot-checks" and a sweep-up survey to count key features or river channel. Whilst it does record many features relevant to hyporheic flow (e.g. vegetation type, artificial structures, channel substrate and emergent bedforms), it does not quantify or map these features at a sub-reach scale, which is the scale used in many empirical studies of hyporheic flow. Spatial resolution explains differences by scale where suitable areas for HEF to occur are predicted only at spatial scales larger than the reach scale (i.e., River Tern and River Rother).

Finally, results in Table 6 depict a scale-dependence effect between catchment and segment scales. The small increment (1 percentage point) in the 
confusion matrix suggests that upper hierarchical levels inform on general conditions at low resolution and exert constraints on the lower level, which informs at higher resolution and provides mechanistic explanation for higher levels.

\subsection{Application to river restoration planning}

This study proposes a multiscale statistical method to identify where HEF potentially occurs at catchment, segment, and reach scale, i.e. an area that is suitable for HEF-based restoration. The approach and results presented in this study use readily available environmental datasets, enabling the method to be transfered to other catchments. Restoration practitioners are increasingly considering the $\mathrm{HZ}$ in their management plans because of the crucial role it plays in river biogeochemical processing and the transferring of solutes and oxygen between surface waters, groundwater and the HZ (Findlay, 1995; Nogaro et al., 2010; Mendoza-Lera and Datry, 2017). Thus, there is a strong need to provide river managers and restoration practitioners with a tool that can be applied to any catchment, and which is flexible enough to work with the data sources available in different regions and countries.

As highlighted by other framework approaches, i.e. REFORM (Gurnell et al., 2014), structuring the analysis around multiple scales improves spatial and temporal understanding of the variability of environmental factors in river systems and how reaches have been impacted by catchment-scale changes. Therefore, our approach supports broader restoration planning that 
includes catchment-scale solutions (Merill and Tonjes, 2014; Wortley et al., 2013; Hester and Gooseff, 2011).

To assist river restoration practitioners, we propose that this multi-scale statistical process be run as a preliminary assessment step in restoration planning to identify and possibly prioritize restoration actions (i.e. reach locations) across a catchment. Restoration managers can benefit from the classification analysis by evaluating how well hydrological, hydrogeological, topographical and ecological factors describe hyporheic drivers (Figure 5). First, by interrogating the clusters generated by Step 2, managers can be informed about: i) environmental and hyporheic-drivers on the targeted areas, ii) identify areas with the same hydrological, hydrogeological, topographical and ecological context, and iii) are spatially unique. Second, by examining the final confusion matrices (Step 4), which embed a summary of knowledge across the domains of hydrology, geology, and hyporheic theories and their related environmental data, and provide insights into the spatial variability of HEF in a catchment. Finally, by using the results of the multi-scale assessment (Step 5), river managers can define a posteriori what processes management actions are important for each reaches and then feedback to management actions. 


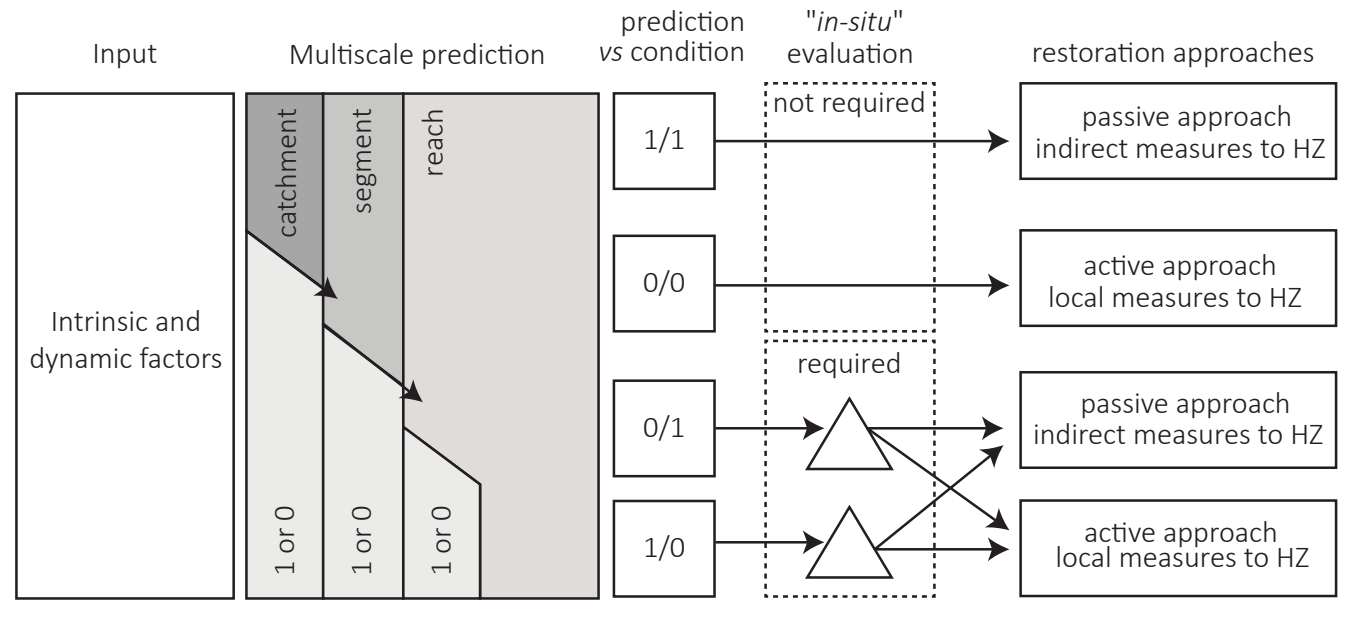

Figure 5: Multiscale prediction of hyporheic flows using intrinsic (i.e. aquifer type, bedrock geology) and dynamic factors (i.e. land use, superficial sediment) and potential restoration approaches. "1" refers to likely presence of HEF and "0" to unlikely presence of HEF. The definitions of terms can be found in the text.

Considering the above information, river managers can choose between "passive" and "active" approaches. For example, some of the factors depicted in the clusters will be intrinsic (i.e. bedrock geology) and cannot be changed by management measures, while others will be dynamic (i.e. land use, vegetation, channel geomorphology) and therefore might become a target for catchment or river management. If suitable HEF conditions are predicted, a passive approach will likely be preferred and include measures that do not directly address hyporheic conditions but that take advantage of HEF to preserve and maintain, for example, habitat diversity or soil erosion reduction (The River Restoration Centre, 2013). The passive approach would include in-situ evaluation to verify that the method predictions are representative of 
local conditions. Conversely, if unsuitable HEF conditions are predicted, an active approach can be adopted, and local or restoration measures applied accordingly to the factors involved. For example, the case study on the River Rother showed suitable conditions for HEF to occur at catchment scale (i.e. complex aquifer, gravel to sand deposits), while unsuitable conditions were predicted in segments and reaches (i.e. low channel gradient and sinuosity, clay and lenses). An active restoration approach would be appropriate to implement local restoration measures for enhancing local hyporheic flows and ecological functioning in this river (Figure 5).

In our opinion, the identified factors for HEF have intuitive general validity, but we expect that in other applications the method would be tailored to site-specific characteristics and applied to other factors. At reach and sub-reach scales, the classification is generally limited by the resolution and quality of the available data. This is a general issue when using environmental surrogates of hydrological processes, especially due to the coarse resolution of the data (Olden et al., 2012). We qualitatively compared the prediction of the method on available empirical hyporheic evidence that was i) spatially and temporally limited to local scales, ii) collected using multiple methods, and iii) focused on specific geomorphic features, such as bedforms, that likely trigger local advective HEF even when catchment conditions limit larger-scale flows. In the future, we expect this evidence-based problem to be overcome by technology and more complete and uniform metadata associated with hyporheic studies. 
Finally, existing scientific literature suggests that knowing how and what to prioritize in restoration actions for aquatic ecosystems are fundamental to effective restoration planning (Wohl et al., 2005). There is an increasing emphasis on addressing hyporheic zones into restoration to allow more comprehensive hydro-ecological understanding of aquatic ecosystems; our model can support restoration as a first-order assessment to target $\mathrm{HZ}$ and thus provide the greatest benefits to restoration plans.

\section{Acknowledgements}

This work was supported by the Marie Sklodowska-Curie Action, Horizon2020 within the project HypoTRAIN (Grant agreement number 641939); G. Coro was also supported by the BlueBRIDGE project (Grant agreement number 675680); A.I. Packman was also supported by the U.S. National Science Foundation (Grant agreement number EAR-1344280). We thank the Networked Multimedia Information Systems Laboratory (Ne-MIS), Research Laboratory of ISTI-CNR Italy, for providing full support for the development of this research, the Biebrza National Park for providing the needed data for the development of the River Biebrza case of study (data sources: "Preservation of wetland habitats in the upper Biebrza Valley LIFE11/NAT/PL/422" and "Restoration of hydrological system in Middle Basin of the Biebrza Valley. Phase I. LIFE project." Thanks to Dr. Christian Anibas for his availability in sharing information on the River Biebrza, the Environment Agency

and Dr. Marc Naura who provided the River Habitat Survey data for the 
U.K. catchments. We thank the British Geological Survey, the Centre for Ecology \& Hydrology, the UK Met Office, the European Soil Data Centre, the European Environment Agency and the Polish Geological Institute as data providers. We also thank Prof. Ian Holman and the three anonymous reviewers for their helpful comments on the manuscript.

\section{Author Contributions}

Chiara Magliozzi conceived, designed and analysed the dataset producing and assessing the final clusters. Gianpaolo Coro supervised the whole design and contributed to the development of the methodology from the statistical perspective. Robert Grabowski, Aaron Packman, and Stefan Krause provided hydrological and hydromorphological perspectives. All authors read and approved the manuscript.

\section{Conflicts of Interest}

The authors declare no conflicts of interest.

\section{References}

Anderson, J.K., Wondzell, S.M., Gooseff, M.N., Haggerty, R., 2005. Patterns in stream longitudinal profiles and implications for hyporheic exchange flow at the HJ Andrews Experimental Forest, Oregon, USA. Hydrological Processes 19, 2931-2949. 
Anibas, C., Verbeiren, B., Buis, K., Chormanski, J., De Doncker, L., Okruszko, T., Meire, P., Batelaan, O., 2012. A hierarchical approach on groundwater-surface water interaction in wetlands along the upper Biebrza River, Poland. Hydrology and Earth System Sciences 16, 2329.

Aubeneau, A.F., Drummond, J.D., Schumer, R., Bolster, D., Tank, J.L., Packman, A.I., 2015. Effects of benthic and hyporheic reactive transport on breakthrough curves. Freshwater Science 34, 301-315.

Bardini, L., Boano, F., Cardenas, M., Revelli, R., Ridolfi, L., 2012. Nutrient cycling in bedform induced hyporheic zones. Geochimica et Cosmochimica Acta 84, 47-61.

Battin, T.J., Besemer, K., Bengtsson, M.M., Romani, A.M., Packmann, A.I., 2016. The ecology and biogeochemistry of stream biofilms. Nature Reviews Microbiology 14, 251-263.

Battin, T.J., Kaplan, L.A., Findlay, S., Hopkinson, C.S., Marti, E., Packman, A.I., Newbold, J.D., Sabater, F., 2008. Biophysical controls on organic carbon fluxes in fluvial networks. Nature Geoscience 1, 95.

Bentley, J.L., 1975. Multidimensional binary search trees used for associative searching. Communications of the ACM 18, 509-517.

Berezowski, T., Szcześniak, M., Kardel, I., Michałowski, R., Okruszko, T., Mezghani, A., Piniewski, M., 2016. CPLFD-GDPT5: High-resolution grid- 
ded daily precipitation and temperature data set for two largest Polish river basins. Earth System Science Data 8, 127-139.

Bilotta, G., Brazier, R., 2008. Understanding the influence of suspended solids on water quality and aquatic biota. Water research 42, 2849-2861.

Bilotta, G., Krueger, T., Brazier, R., Butler, P., Freer, J., Hawkins, J., Haygarth, P.M., Macleod, C., Quinton, J.N., 2010. Assessing catchment-scale erosion and yields of suspended solids from improved temperate grassland. Journal of Environmental Monitoring 12, 731-739.

Boano, F., Camporeale, C., Revelli, R., Ridolfi, L., 2006. Sinuosity-driven hyporheic exchange in meandering rivers. Geophysical Research Letters $33,1-4$.

Boano, F., Harvey, J.W., Marion, A., Packman, A.I., Revelli, R., Ridolfi, L., Wörman, A., 2014. Hyporheic flow and transport processes: Mechanisms, models, and biogeochemical implications. Reviews of Geophysics 52, 603679.

Boulton, A., Hancock, P., 2006. Rivers as groundwater-dependent ecosystems: a review of degrees of dependency, riverine processes and management implications. australian Journal of Botany 54, 133-144.

Boulton, A.J., 2007. Hyporheic rehabilitation in rivers: restoring vertical connectivity. Freshwater Biology 52, 632-650. 
Brunke, M., Gonser, T., 1997. The ecological significance of exchange processes between rivers and groundwater. Freshwater biology 37, 1-33.

Byczkowski, A., B., F., 2004. Kotlina Biebrzańska i Biebrzański Park Narodowy. Aktualny stan, walory, zagroenia i potrzeby czynnej ochrony środowiska. Monografia przyrodnicza, Białystok. pp. 113-167.

Cardenas, M.B., 2007. Potential contribution of topography-driven regional groundwater flow to fractal stream chemistry: Residence time distribution analysis of tóth flow. Geophysical Research Letters 34.

Cardenas, M.B., 2008. Surface water-groundwater interface geomorphology leads to scaling of residence times. Geophysical Research Letters 35.

Cardenas, M.B., 2015. Hyporheic zone hydrologic science: A historical account of its emergence and a prospectus. Water Resources Research 51, 3601-3616.

Cardenas, M.B., Wilson, J., Zlotnik, V.A., 2004. Impact of heterogeneity, bed forms, and stream curvature on subchannel hyporheic exchange. Water Resources Research 40.

Cardenas, M.B., Wilson, J.L., 2007. Effects of current-bed form induced fluid flow on the thermal regime of sediments. Water resources research 43.

Caruso, A., Ridolfi, L., Boano, F., 2016. Impact of watershed topography on hyporheic exchange. Advances in Water Resources 94, 400-411. 
Cohen, J., 1960. A coefficient of agreement for nominal scales. Educational and Psychosocial Measurement, 20, 37-46.

Collins, A., Walling, D., 2007. Fine-grained bed sediment storage within the main channel systems of the frome and piddle catchments, dorset, uk. Hydrological Processes 21, 1448-1459.

Corenblit, D., Tabacchi, E., Steiger, J., Gurnell, A.M., 2007. Reciprocal interactions and adjustments between fluvial landforms and vegetation dynamics in river corridors: a review of complementary approaches. EarthScience Reviews 84, 56-86.

Coro, G., Candela, L., Pagano, P., Italiano, A., Liccardo, L., 2015. Parallelizing the execution of native data mining algorithms for computational biology. Concurrency and Computation: Practice and Experience $27,4630-4644$.

Coro, G., Gioia, A., Pagano, P., Candela, L., 2013. A service for statistical analysis of marine data in a distributed e-infrastructure. Bollettino di Geofisica Teorica e Applicata 54, 68-70.

Corson-Rikert, H.A., Wondzell, S.M., Haggerty, R., Santelmann, M.V., 2016. Carbon dynamics in the hyporheic zone of a headwater mountain stream in the cascade mountains, oregon. Water Resources Research 52, 7556-7576.

Cotton, J., Wharton, G., Bass, J., Heppell, C., Wotton, R., 2006. The effects 
of seasonal changes to in-stream vegetation cover on patterns of flow and accumulation of sediment. Geomorphology 77, 320-334.

Danczak, R.E., Sawyer, A.H., Williams, K.H., Stegen, J.C., Hobson, C., Wilkins, M.J., 2016. Seasonal hyporheic dynamics control coupled microbiology and geochemistry in colorado river sediments. Journal of Geophysical Research: Biogeosciences 121, 2976-2987.

Didoné, E.J., Minella, J.P.G., Reichert, J.M., Merten, G.H., Dalbianco, L., de Barrros, C.A.P., Ramon, R., 2014. Impact of no-tillage agricultural systems on sediment yield in two large catchments in southern brazil. Journal of soils and sediments 14, 1287-1297.

Ding, C., He, X., 2004. K-means clustering via principal component analysis, in: Proceedings of the twenty-first international conference on Machine learning, ACM. p. 29.

Dole-Olivier, M.J., Maazouzi, C., Cellot, B., Fiers, F., Galassi, D.M., Claret, C., Martin, D., Merigoux, S., Marmonier, P., 2014. Assessing invertebrate assemblages in the subsurface zone of stream sediments (0-15 cm deep) using a hyporheic sampler. Water Resources Research 50, 453-465.

Dragoni, W., Sukhija, B.S., 2008. Climate change and groundwater: a short review. Geological Society, London, Special Publications 288, 1-12.

Drummond, J., Davies-Colley, R., Stott, R., Sukias, J., Nagels, J., Sharp, A., 
Packman, A., 2014. Retention and remobilization dynamics of fine particles and microorganisms in pastoral streams. water research 66, 459-472.

Dugdale, S.J., Malcolm, I.A., Kantola, K., Hannah, D.M., 2018. Stream temperature under contrasting riparian forest cover: Understanding thermal dynamics and heat exchange processes. Science of The Total Environment $610,1375-1389$.

Dunscombe, M., 2011. The influence of hydrogeology and the Devensian glaciation on hyporheic communities of the UK. Ph.D. thesis. Roehampton University.

Elliott, A.H., Brooks, N.H., 1997. Transfer of nonsorbing solutes to a streambed with bed forms: Theory. Water Resources Research 33, 123136.

Ensign, S.H., Doyle, M.W., 2005. In-channel transient storage and associated nutrient retention: Evidence from experimental manipulations. Limnology and Oceanography 50, 1740-1751.

Ester, M., Kriegel, H.P., Sander, J., Xu, X., 1996. A density-based algorithm for discovering clusters in large spatial databases with noise., in: Kdd, pp. 226-231.

Findlay, S., 1995. Importance of surface-subsurface exchange in stream ecosystems: The hyporheic zone. Limnology and oceanography 40, 159 164. 
Fox, A., Boano, F., Arnon, S., 2014. Impact of losing and gaining streamflow conditions on hyporheic exchange fluxes induced by dune-shaped bed forms. Water Resources Research 50, 1895-1907.

Fuller, C.C., Harvey, J.W., 2000. Reactive uptake of trace metals in the hyporheic zone of a mining-contaminated stream, Pinal Creek, Arizona. Environmental Science \& Technology 34, 1150-1155.

Gibbins, C., Grant, J., Malcolm, I., Soulsby, C., 2016. Influence of groundwater chemistry on hyporheic invertebrate assemblages is revealed by finescale sampling. Fundamental and Applied Limnology/Archiv für Hydrobiologie 187, 207-221.

Gomez-Velez, J.D., Harvey, J.W., 2014. A hydrogeomorphic river network model predicts where and why hyporheic exchange is important in large basins. Geophysical Research Letters 41, 6403-6412.

Gooseff, M.N., Hall, R.O., Tank, J.L., 2007. Relating transient storage to channel complexity in streams of varying land use in Jackson Hole, Wyoming. Water Resources Research 43, n/a-n/a.

Gordon, R.P., Lautz, L.K., Daniluk, T.L., 2013. Spatial patterns of hyporheic exchange and biogeochemical cycling around cross-vane restoration structures: Implications for stream restoration design. Water Resources Research 49, 2040-2055. 
Grabowski, R., Gurnell, A., 2016. Diagnosing problems of fine sediment delivery and transfer in a lowland catchment. Aquatic sciences 78, 95-106.

Grabowski, R.C., Surian, N., Gurnell, A.M., 2014. Characterizing geomorphological change to support sustainable river restoration and management. Wiley Interdisciplinary Reviews: Water 1, 483-512.

Gurnell, A., Belletti, B., Bizzi, S., Blamauer, B., Braca, G., Buijse, T., Bussettini, M., Camenen, B., Comiti, F., Demarchi, L., et al., 2014. A hierarchical multi-scale framework and indicators of hydromorphological processes and forms. deliverable 2.1, a report in four parts of reform (restoring rivers for effective catchment management), a collaborative project (largescale integrating project) funded by the european commission within the 7th framework programme under grant agreement 282656.

Hannah, D.M., Malcolm, I.A., Bradley, C., 2009. Seasonal hyporheic temperature dynamics over riffle bedforms. Hydrological Processes 23, 2178-2194.

Hartwig, M., Borchardt, D., 2015. Alteration of key hyporheic functions through biological and physical clogging along a nutrient and fine-sediment gradient. Ecohydrology 8, 961-975.

Harvey, J.W., Bencala, K.E., 1993. The effect of streambed topography on surface-subsurface water exchange in mountain catchments. Water Resources Research 29, 89-98. 
Heppell, C., Heathwaite, A.L., Binley, A., Byrne, P., Ullah, S., Lansdown, K., Keenan, P., Trimmer, M., Zhang, H., 2014. Interpreting spatial patterns in redox and coupled water-nitrogen fluxes in the streambed of a gaining river reach. Biogeochemistry 117, 491-509.

Hester, E.T., Cardenas, M.B., Haggerty, R., Apte, S.V., 2017. The importance and challenge of hyporheic mixing. Water Resources Research 53, $3565-3575$.

Hester, E.T., Doyle, M.W., 2008. In-stream geomorphic structures as drivers of hyporheic exchange. Water Resources Research 44.

Hester, E.T., Gooseff, M.N., 2011. Hyporheic restoration in streams and rivers. Stream Restoration in Dynamic Fluvial Systems , 167-187.

Hester, E.T., Hammond, B., Scott, D.T., 2016. Effects of inset floodplains and hyporheic exchange induced by in-stream structures on nitrate removal in a headwater stream. Ecological Engineering 97, 452-464.

Hiscock, K., 2007. Hydrogeology: Principles and Practice. Blackwell publishing, Oxford.

Jolliffe, I., 2002. Principal component analysis. Wiley Online Library.

Jones, K.L., Poole, G.C., Woessner, W.W., Vitale, M.V., Boer, B.R., O'Daniel, S.J., Thomas, S.A., Geffen, B.A., 2008. Geomorphology, hydrology, and aquatic vegetation drive seasonal hyporheic flow patterns across a gravel-dominated floodplain. Hydrological Processes 22, 2105-2113. 
Kasahara, T., Wondzell, S.M., 2003. Geomorphic controls on hyporheic exchange flow in mountain streams. Water Resources Research 39.

Kasahara, T., Yasuda, Y., Otsuki, K., 2013. Changes in distribution of fine sediments in the hyporheic zone during high flow events, in: AGU Fall Meeting Abstracts.

Kennard, M.J., Mackay, S.J., Pusey, B.J., Olden, J.D., Marsh, N., 2010. Quantifying uncertainty in estimation of hydrologic metrics for ecohydrological studies. River Research and Applications 26, 137-156.

Krause, S., Hannah, D., Fleckenstein, J., Heppell, C., Kaeser, D., Pickup, R., Pinay, G., Robertson, A., Wood, P., 2011. Inter-disciplinary perspectives on processes in the hyporheic zone. Ecohydrology 4, 481-499.

MacQueen, J., 1967. Some methods for classification and analysis of multivariate observations, in: Proceedings of the fifth Berkeley symposium on mathematical statistics and probability, California, USA. pp. 281-297.

Malzone, J.M., Anseeuw, S.K., Lowry, C.S., Allen-King, R., 2015. Temporal Hyporheic Zone Response to Water Table Fluctuations. Groundwater .

Malzone, J.M., Lowry, C.S., Ward, A.S., 2016. Response of the hyporheic zone to transient groundwater fluctuations on the annual and storm event time scales. Water Resources Research .

Mendoza-Lera, C., Datry, T., 2017. Relating hydraulic conductivity and 
hyporheic zone biogeochemical processing to conserve and restore river ecosystem services. Science of The Total Environment 579, 1815-1821.

Merill, L., Tonjes, D.J., 2014. A Review of the Hyporheic Zone, Stream Restoration, and Means to Enhance Denitrification. Critical Reviews in Environmental Science and Technology 44, 2337-2379.

Morrice, J.a., Valett, H.M., Dahm, C.N., Campana, M.E., 1997. Alluvial Characteristics, Groundwater-Surface Water Exchange and Hydrological Retention in Headwater Streams. Hydrological Processes 11, 253-267.

Nogaro, G., Datry, T., Mermillod-Blondin, F., Descloux, S., Montuelle, B., 2010. Influence of streambed sediment clogging on microbial processes in the hyporheic zone. Freshwater biology 55, 1288-1302.

Olden, J.D., Kennard, M.J., Pusey, B.J., 2012. A framework for hydrologic classification with a review of methodologies and applications in ecohydrology. Ecohydrology 5, 503-518.

Orghidan, T., 1959. Ein neuer Lebensraum des unterirdischen Wassers: der hyporheische Biotop. Arch. Hydrobiol 55, 392-414.

Packman, A.I., Marion, A., Zaramella, M., Chen, C., Gaillard, J.F., Keane, D.T., 2006. Development of layered sediment structure and its effects on pore water transport and hyporheic exchange. Water, Air, \& Soil Pollution: Focus 6, 433-442. 
Packman, A.I., Salehin, M., 2003. Relative roles of stream flow and sedimentary conditions in controlling hyporheic exchange, in: The Interactions between Sediments and Water. Springer, pp. 291-297.

Palmer, M.A., Menninger, H.L., Bernhardt, E., 2010. River restoration, habitat heterogeneity and biodiversity: a failure of theory or practice? Freshwater biology 55, 205-222.

Palumbo-Roe, B., Banks, V.J., Bonsor, H.C., Hamilton, E.M., Watts, M.J., 2017. Limitations on the role of the hyporheic zone in chromium natural attenuation in a contaminated urban stream. Applied Geochemistry .

Pelleg, D., Moore, A.W., et al., 2000. X-means: Extending K-means with Efficient Estimation of the Number of Clusters., in: ICML.

Pretty, J., Hildrew, A., Trimmer, M., 2006. Nutrient dynamics in relation to surface-subsurface hydrological exchange in a groundwater fed chalk stream. Journal of Hydrology 330, 84-100.

Raven, P., Fox, P., Everard, M., Holmes, N., Dawson, F.H., 1996. River Habitat Survey: a new system for classifying rivers according to their habitat quality.

Rezanezhad, F., Price, J.S., Quinton, W.L., Lennartz, B., Milojevic, T., Van Cappellen, P., 2016. Structure of peat soils and implications for water storage, flow and solute transport: A review update for geochemists. Chemical Geology 429, 75-84. 
Robertson, A., Wood, P., 2010. Ecology of the hyporheic zone: origins, current knowledge and future directions. Fundamental and Applied Limnology/Archiv für Hydrobiologie 176, 279-289.

Ryan, R.J., Welty, C., Larson, P.C., 2010. Variation in surface watergroundwater exchange with land use in an urban stream. Journal of hydrology 392, 1-11.

Salehin, M., Packman, A.I., Paradis, M., 2004. Hyporheic exchange with heterogeneous streambeds: Laboratory experiments and modeling. Water Resources Research 40.

Schirmer, M., Luster, J., Linde, N., Perona, P., Mitchell, E.A., Barry, D.A., Hollender, J., Cirpka, O.A., Schneider, P., Vogt, T., et al., 2014. Morphological, hydrological, biogeochemical and ecological changes and challenges in river restoration. Hydrology and Earth System Sciences 18, 2449.

Sobczak, W.V., Findlay, S., 2002. Variation in bioavailability of dissolved organic carbon among stream hyporheic flowpaths. Ecology 83, 3194-3209.

Stonedahl, S.H., Harvey, J.W., Wörman, A., Salehin, M., Packman, A.I., 2010. A multiscale model for integrating hyporheic exchange from ripples to meanders. Water Resources Research 46.

Storey, R.G., Howard, K.W., Williams, D.D., 2003. Factors controlling rifflescale hyporheic exchange flows and their seasonal changes in a gaining 
stream: A three-dimensional groundwater flow model. Water Resources Research 39 .

The River Restoration Centre, 2013. The manual of river restoration techniques. URL: http://www.therrc.co.uk/ manual-river-restoration-techniques.

Tonina, D., Buffington, J.M., 2009. Hyporheic exchange in mountain rivers I: Mechanics and environmental effects. Geography Compass 3, 1063-1086.

Trimble, S.W., Mendel, A.C., 1995. The cow as a geomorphic agenta critical review. Geomorphology 13, 233-253.

Triska, F.J., Duff, J.H., Avanzino, R.J., 1993. The role of water exchange between a stream channel and its hyporheic zone in nitrogen cycling at the terrestrial-aquatic interface. Hydrobiologia 251, 167-184.

Tuttle, A.K., McMillan, S.K., Gardner, A., Jennings, G.D., 2014. Channel complexity and nitrate concentrations drive denitrification rates in urban restored and unrestored streams. Ecological engineering 73, 770-777.

Voltz, T., Gooseff, M., Ward, A.S., Singha, K., Fitzgerald, M., Wagener, T., 2013. Riparian hydraulic gradient and stream-groundwater exchange dynamics in steep headwater valleys. Journal of Geophysical research: Earth Surface 118, 953-969.

Walling, D., Amos, C., 1999. Source, storage and mobilisation of fine sediment in a chalk stream system. Hydrological processes 13, 323-340. 
Ward, A.S., 2016. The evolution and state of interdisciplinary hyporheic research. Wiley Interdisciplinary Reviews: Water 3, 83-103.

Ward, A.S., Fitzgerald, M., Gooseff, M.N., Voltz, T.J., Binley, A.M., Singha, K., 2012. Hydrologic and geomorphic controls on hyporheic exchange during base flow recession in a headwater mountain stream. Water Resources Research 48 .

Waters, A., Banks, D., 1997. The chalk as a karstified aquifer: closed circuit television images of macrobiota. Quarterly Journal of Engineering Geology and Hydrogeology 30, 143-146.

Wohl, E., Angermeier, P.L., Bledsoe, B., Kondolf, G.M., MacDonnell, L., Merritt, D.M., Palmer, M.A., Poff, N.L., Tarboton, D., 2005. River restoration. Water Resources Research 41.

Wondzell, S., Gooseff, M., 2013. Geomorphic controls on hyporheic exchange across scales: watersheds to particles. Treatise on Geomorphology 9, 203218.

Wondzell, S.M., Swanson, F.J., 1996. Seasonal and storm dynamics of the hyporheic zone of a 4th-order mountain stream. I: Hydrologic processes. Journal of the North American Benthological Society 15, 3-19.

Wood, P., Armitage, P., 1999. Sediment deposition in a small lowland streammanagement implications. River Research and Applications 15, 199-210. 
Wörman, A., Packman, A.I., Marklund, L., Harvey, J.W., Stone, S.H., 2006. Exact three-dimensional spectral solution to surface-groundwater interactions with arbitrary surface topography. Geophysical research letters 33.

Wörman, A., Packman, A.I., Marklund, L., Harvey, J.W., Stone, S.H., 2007. Fractal topography and subsurface water flows from fluvial bedforms to the continental shield. Geophysical Research Letters 34.

Wortley, L., Hero, J.M., Howes, M., 2013. Evaluating ecological restoration success: a review of the literature. Restoration Ecology 21, 537-543.

Wroblicky, G.J., Campana, M.E., Valett, H.M., Dahm, C.N., 1998. Seasonal variation in surface-subsurface water exchange and lateral hyporheic area of two stream-aquifer systems. Water Resources Research 34, 317.

Zarnetske, J.P., Haggerty, R., Wondzell, S.M., Baker, M.A., 2011. Dynamics of nitrate production and removal as a function of residence time in the hyporheic zone. Journal of Geophysical Research: Biogeosciences 116. 